\title{
Un desconocido incidente periodístico de Ricardo Palma'
}

Por Alberto Varillas Montenegro

1 Este trabajo se presentó en la jornada titulada Re-visión de las Tradiciones correspondiente al año 2014 que convoca anualmente el Instituto Ricardo Palma de la Universidad Ricardo Palma con el título de La Sabatina, Luis Enrique Márquez y Ricardo Palma. A la versión original, se han incorporado algunas breves adiciones relacionadas con los textos de Palma aparecidos en los semanarios Cascabel y La Sabatina. 
Realizó sus estudios en la Facultad de Letras y en la Facultad de Derecho y Ciencias Políticas de la Pontificia Universal Católica del Perú. Es presidente del Patronato de la Casa Museo Ricardo Palma. 
Este trabajo se refiere a un incidente que no ha merecido atención alguna de los estudiosos de la literatura del siglo XIX peruano, pero que, si se analiza con la óptica de ciento cincuenta años atrás, es posible reparar en que a principios de la década de 1870 resultaba sumamente importante. En este incidente hay cuatro componentes: el primero es la participación de Ricardo Palma en el semanario limeño Cascabel, de carácter netamente político destinado a atacar al Partido Civil que el 2 de agosto de 1872 había asumido el mando político en el Perú mediante el gobierno encabezado por don Manuel Pardo y Lavalle; el segundo es la reacción contra Palma desde el semanario La Sabatina, también limeño, pues los pocos que se han ocupado de él se limitan a señalar que apoyó la candidatura de Manuel Pardo a la presidencia de la república; el tercero es la vida y obra de Luis Enrique Márquez, periodista agresivo y muy aceptable versificador que ha sido marginado por nuestras historias de la literatura que solo le conceden el mérito de haber fundado La Sabatina, haber sido uno de los fundadores y el primer presidente del Círculo Literario y haber estado claramente vinculado a La Revista Social; y el cuarto es el posible origen de la animadversión de algunos periodistas contra Ricardo Palma que se inicia con los textos que se le dedica en La Sabatina y no con los discursos de González Prada de la segunda mitad de la década de 1880, como hasta ahora se repite. 


\section{El colapso político de Palma}

Ricardo Palma fue, durante toda su vida, un fervoroso seguidor de la vida política peruana, vocación que le había generado dificultades que se remontan casi hasta su pubertad y que llegaron a su punto culminante cuando se ve obligado a partir rumbo al exilio dada su participación en el atentado contra el presidente general Castilla en noviembre de 1860. Años después, en 1867, Palma se incorpora a las fuerzas revolucionarias del coronel José Balta quien al año siguiente asume la presidencia de la república y lo lleva como secretario particular en el despacho presidencial y favorece su elección como senador por Loreto ${ }^{2}$.

Sin embargo, desde 1871 comienzan a tener lugar en el Perú diversos hechos que hacían presagiar inminentes dificultades políticas: con el nombre de Sociedad Independencia Electoral se había fundado el 24 de abril de 1871 lo que luego se convertiría en el Partido Civil, que buscaba postular a la presidencia a un candidato no-militar; en el mes de octubre del mismo año se había convocado a elecciones generales previéndose que la transmisión del mando tendría lugar en agosto del año siguiente; había surgido un joven candidato civil de oposición, Manuel Pardo, que había ganado un reconocimiento general como alcalde de Lima; el gobierno de Balta, que había surgido como consecuencia del triunfo de la revolución que había encabezado contra Mariano Ignacio Prado, comienza a resquebrajarse pues no lograba encontrar un candidato propio. Por último, se desató una terrible guerra periodística por cuando cada posible candidato tenía un diario o revista que lo apoyaba. La violencia avanzaba y en setiembre

2 Palma ocupó el cargo de secretario particular del presidente de la república tan pronto como Balta asume el mando en agosto de 1868; Se desempeñó como senador por la Provincia Litoral de Loreto entre el 17 de julio de 1868 y la conclusión de la Legislatura Extraordinaria de 1872, el 28 de abril de 1873: los del gobierno de Balta fueron, pues, los años del apogeo político de Palma. 
de 1871 se llega al extremo de que el presidente Balta convoca a su despacho a los tres candidatos de ese momento: Manuel Toribio Ureta (1813-1875), Manuel Pardo (1834-1878) y el ex presidente José Rufino Echenique (1808-1887) en un esfuerzo infructuoso para buscar un candidato de consenso y darle continuidad al régimen democrático que se había inaugurado con él.

El 15 de noviembre de 187 I se realizaron las elecciones en que se designaban a los integrantes de los Colegios Electorales y, según iban llegando las actas de provincias, parecía evidente el triunfo de Pardo. Era la primera vez en la historia del Perú que iba a ganar la oposición. Mientras el país se preparaba para la inauguración de la Exposición nacional, reinaba una gran confusión política que se arrastraba desde tiempo atrás y que había conducido a la clausura de dos de los diarios que apoyaban a Pardo (El Nacional, en noviembre de 1871; El Comercio, en mayo de 1872). Finalmente, en julio de 1872, cuando faltaban diez días para la conclusión de su gobierno, el coronel Balta es asesinado cobardemente, el vicepresidente coronel Mariano Herencia Zevallos asume por diez días la presidencia de la república y el 2 de agosto recibe el mando supremo don Manuel Pardo, el primer presidente civil del país.

\section{El Cascabel}

Culminados los dramáticos incidentes que rodearon el cruento cambio de mando, Palma continúa ejerciendo su actividad como senador pero, hombre inquieto, sucumbe ante la tentación de volver al periodismo, actividad en la que se había iniciado medio siglo antes (desde 1848, en El Diablo); y así, algún tiempo después se le encuentra en El Cascabel, semanario político que se hace merecedor a la censura de Raúl Porras: "El Cascabel suma 
agudezas e injurias contra el presidente [Pardo] y sus ministros."3 Hasta hoy nadie había siquiera insinuado la presencia de Palma en El Cascabel: pero La Sabatina la descubre.

Para los estudiosos del siglo XIX, El Cascabel fue un semanario que pasó inadvertido entre 1872 y 1874 . Circuló los sábados ${ }^{4}$ a partir del 26 de octubre de 1872 con un formato de 43 por $26 \mathrm{~cm}$. Después de una interrupción de casi un año -cuyos extremos no son posibles de precisar-, El Cascabel reaparece en 1874: su $\mathrm{N}^{\circ} 39$ es del 14 de febrero y el último que se le conoce es el $\mathrm{N}^{\circ} 46$, del 4 de abril de ese año. Lo que se debe reconocer es la regularidad de sus apariciones.

La información bibliográfica existente sobre este semanario es muy confusa: en 1879, Paz Soldán indica que apareció 24 veces en 1872, lo cual es un error; en 1924, Odriozola registra en la Biblioteca Nacional una colección casi completa desde su primer número hasta el $\mathrm{N}^{\circ} 68$, de 5 de setiembre de $1874^{5}$; después del incendio de 1843, el catálogo elaborado por la propia Biblioteca Nacional consigna solo 10 números, el último de los cuales, el $\mathrm{N}^{\circ} 46$, es del 4 de abril de 1874. iMás de medio ciento de sus ejemplares habían desaparecido!

Inicialmente, El Cascabel se publicó en la Imprenta de La Nación por Mariano Murga; posteriormente pasa a serlo en la Imprenta de El Pueblo, por Mariano Oberti. Todos los números conocidos son de 4 págs. y contienen ilustraciones de

3 Raúl Porras Barrenechea, El periodismo en el Perú. Ciento veinte años de periódicos. [En:] Mundial. Lima, 28 de julio de 1821.

4 Paz Soldán le atribuye 24 apariciones en 1872, lo cual es incorrecto puesto que el $\mathrm{N}^{\circ} \mathrm{l}$ es del 26 de octubre y entre esa fecha y el fin del año solo quedaban 10 semanas; podría haberse referido no al año 1872 sino a su primer año de vida, lo cual por ahora no es comprobable.

5 Manuel de Odriozola, Catálogo de los periódicos nacionales existentes en la Biblioteca Nacional. [En:] Boletín bibliográfico publicado por la Biblioteca de la Universidad Mayor de San Marcos, 1924. 
gran tamaño: la correspondiente al $N^{\circ} 1$, cubre las dos páginas centrales. Su precio era de un real o de cinco reales mensuales: se distribuía gratuitamente a los suscriptores de La Nación ${ }^{6}$.

El Cascabel tiene columnas similares a todas las que aparecían en las publicaciones que cumplían los mismos propósitos en el siglo XIX peruano: Editorial, Retratos parlamentarios, Pinceladas y más adelante Pinceladitas, Parte colaboratil (comunicaciones o protestas), Cascabeles, Palotadas... Todas las secciones se prestaban, pues, al ataque político encubierto.

Ninguna de las columnas de El Cascabel tiene nombre: todas llevan seudónimos ingeniosos: Don Justo de las Figuras Claras, Don Blas de los Palos Secos, Don Gaspar del Pincel Delgado, Canuto Cañas Bravas, etc.

Siguiendo a Paz Soldán, se suponía que sus redactores eran Adolfo Valdez y Benito Neto ${ }^{7}$. Sin embargo, el ejemplar existente en la Biblioteca Nacional del Perú contiene anotaciones manuscritas de don Ricardo Palma, correspondientes a los años en que fue su Director, que obligan a incorporar a su nómina de redactores a Julio Lucas Jaimes y a Federico Salmón. Más aún, por los ataques contra El Cascabel contenidos en La Sabatina, se deduce que Ricardo Palma tenía en El Cascabel una columna de fuerte ataque al gobierno. En efecto, en la Galería periodística de La Sabatina, en columna titulada Ricardo Palma, que es de difícil lectura pues el ejemplar que tenemos a la vista se encuentra incompleto y bastante quemado en los bordes, aparecen los siguientes párrafos:

6 La Nación fue un diario político y comercial que circuló en Lima entre abril de 1872 y agosto de 1873 .

7 Mariano Felipe Paz Soldán, Biblioteca peruana, entrada 122. 
"Su sección en "El Cascabel" es la más negra de los pasquines habidos y por haber. / Es acérrimo enemigo del actual gobierno que trata de rehacer la nacional fortuna de la Nación entera y aborrece [...] al sicario del derroche" ${ }^{\text {. }}$

Adolfo Valdés fue un periodista y poeta colombiano avecindado en el Perú desde antes de 1865. En Lima publicó unos Ensayos líricos (1868); cabría aceptar que fue uno de los redactores de El Cascabel, siguiendo a Paz Soldán, puesto que todos los artículos son anónimos; publicó una docena de sus versos en El Correo del Perú entre 1872 y 1873. Posiblemente por razones de salud, se embarca hacia Chile en los primeros meses de 1873 y aparentemente fallece en Valparaíso después del 30 de junio del mismo año?.

Benito Neto era un experimentado periodista uruguayo que había dirigido La Tribuna en Montevideo y prestado servicios en otros diarios sudamericanos. En el Perú estuvo vinculado a Piérola aunque fue redactor de El Cascabel. Hizo, como periodista, la campaña del sur durante la Guerra del Pacífico y falleció en Lima a fines de 1884.

Julio Lucas Jaimes (1845-1914) fue un político y periodista boliviano designado cónsul de Bolivia en Tacna, donde casó con la escritora peruana Carolina Freyre (1844-1916). Perdido el favor político, pasó a Lima donde ejerció como periodista de diversos diarios hasta los años de la Guerra del Pacífico. Durante la guerra favoreció una solución favorable a Chile y Bolivia en detrimento del Perú, lo que le impidió volver al país.

El cuarto de los redactores identificados fue don Ricardo Palma, sobre el cual es innecesario explayarse.

8 La Sabatina, año II, N 30. Lima, sábado 30 de enero de 1873. pág. 2.

9 El Correo del Perú, número extraordinario. Lima, 1873. 
En el ejemplar existente en la Biblioteca Nacional hay dos anotaciones manuscritas de Palma relacionadas con la paternidad de los textos: la primera es “...las semblanzas fueron escritas (sic) Palma"; la segunda es “...las cartas gringas fueron escritas por Federico Salmón”. Pese a las anotaciones, la realidad es diferente porque el mismo tradicionista anota el nombre del autor al final de la gran mayoría de los "Retratos parlamentarios": por ellas debemos entender que Palma preparó la mitad y la otra mitad se dividió en partes iguales entre Neto y Jaimes.

\section{El incidente}

El enojoso incidente del cual Palma es víctima debe haber tenido un desarrollo tal como el que nos atrevemos a sugerir: debe haber comenzado con la aparición del $\mathrm{N}^{\circ} \mathrm{l}$ de El Cascabel y estar relacionada con su frontal oposición al régimen de Pardo que desde los primeros meses de gobierno enfrentaba dificultades derivadas de la situación económica en que se encontraba el país (octubre de 1872); advirtiendo la violencia de los ataques de los cuales era objeto, el gobierno o el Partido Civil debe haber buscado una forma de contrarrestarlos y, luego de algunas semanas, dispone que los editores de La Sabatina, que en 1871 había sido un semanario pardista y había suspendido sus apariciones en el mes de enero de 1872, reaparezca de inmediato con reiteradas energías, lo que ocurre el 28 de diciembre de 1872. La confrontación, pues, se inicia con el fin del año y, puesto que no existen colecciones completas de los dos semanarios, creemos que es válido suponer que dura poco tiempo pues ninguno de los contendores consideraría conveniente mantener una polémica con ofensas de un tono tan desagradablemente vulgar.

Establecido lo anterior, conviene considerar a La Sabatina, el otro extremo de la contienda. 


\section{La Sabatina}

La Sabatina es otra de las tantas publicaciones periódicas peruanas del siglo XIX que no ha merecido mayor atención de los estudiosos de esa época. La Sabatina aparece en momentos en que en el Perú comienzan a barajarse los nombres del posible sucesor del presidente coronel José Balta quien, de no haber sido asesinado unos cuantos días antes, hubiera completado su gobierno constitucional el 2 de agosto de 1872. De La Sabatina -cuyo nombre pone de manifiesto su pretendida periodicidad: los días sábado- no se conoce colección completa alguna $^{10}$; sin embargo, los números que custodia la hemeroteca de la Biblioteca Nacional del Perú -cerca de un tercio del total que logró publicar- y los que cita Zanutelli facilitan una cierta reconstrucción de la revista y permiten establecer con razonable aproximación cuáles fueron los propósitos que perseguía.

La Sabatina fue una publicación periódica que pretendió aparecer en forma semanal, de 4 págs., impresa a cinco columnas. En comparación con otras publicaciones políticas de aquellos años, el semanario tuvo una vida relativamente larga pues apareció entre mediados de 1871 y el primer tercio de 1873 (en aquellos años, una publicación política que subsistía durante cerca de dos años estaba acreditando una duración respetable). La revista tuvo dos formatos diferentes: los números de $187 \mathrm{l}$ y principios de 1872 fueron de 45 por $31.5 \mathrm{~cm}$.; los de fines de 1872 y 1873 , de 38 por $24.5 \mathrm{~cm}$. En un primer momento, su precio fue de cuarenta centavos; en 1873 ya cuesta un real. Los números aparecidos en 1873 tienen encabezamiento distinto de los anteriores. En 1871 y 1872 se publicó en la Imprenta de

10 Estando concluida una primera versión de este trabajo, reparo en que Manuel Zanutelli Rosas, infatigable revisor de archivos y bibliotecas, al preparar una biografía de Luis E. Márquez, da cuenta de la existencia de cuando menos otros tres números que desconocía y que me han sido de mucha utilidad. 
El Nacional, de Benigno Antezana, por Federico I. Masías; en 1873 pasó, con el mismo editor, a la Imprenta de La Sabatina.

Hacen bien quienes, repitiendo a Paz Soldán, han descrito a La Sabatina como un semanario político y humorístico; sin embargo, solo Zanutelli ${ }^{11}$ ha reparado en los aspectos humorísticos en los cuales abunda esta publicación.

En su Biblioteca Peruana, Paz Soldán indica que el primer número de la revista es del 23 de junio de $187 \mathrm{l}$ y el último, el $\mathrm{N}^{\circ}$ 40 , del 5 de abril de 1873, fechas que se han venido repitiendo sin verificar. Zanutelli posterga su aparición hasta el 29 de julio de 1871 y por la manera en que la numeración empalmaría con el primer número conocido -el $\mathrm{N}^{\circ} 9$, de 23 de setiembre de 187 l- nos sentimos en la necesidad de darle la razón.

Las referencias que se tienen de este semanario no son completas: Paz Soldán, autor del primer catálogo de publicaciones periódicas peruanas, no fija el año de su aparición aunque permite intuirlo ${ }^{12}$; Odriozola solo proporciona la lista de los ejemplares que existían en la Biblioteca Nacional, lo que indica que esa colección se encuentra incompleta hace más de 90 años $^{13}$; Basadre se limita a mencionar que Luis E. Márquez fue su director y que apoyó al Partido civil ${ }^{14}$; el minucioso catálogo de publicaciones periódicas publicado por la Biblioteca Nacional del Perú después del incendio que sufrió su hemeroteca en 1943 permite rectificar algunos de los datos proporcionados por Odriozola.

11 Manuel Zanutelli Rosas, Luis Enrique Márquez [En] Periodistas peruanos del siglo XIX. Itinerario biográfico. págs. 189-192.

12 Mariano Felipe Paz Soldán, Biblioteca Peruana. Entrada 744.

13 Manuel Odriozola, Catálogo de los periódicos nacionales existentes en la Biblioteca Nacional, pág. 260.

14 Jorge Basadre, Introducción a las bases documentales para la historia de la república del Perú... Entrada 5999. 
Sin embargo, nadie ha observado hasta ahora que en La Sabatina hay dos etapas claramente diferenciadas: la primera cubre desde su aparición en julio de 1871 (porque estamos aceptando la propuesta de Zanutelli) hasta el $\mathrm{N}^{\circ} 25$, de 21 de enero de 1872; la segunda, desde el $\mathrm{N}^{\circ} 26$, del 28 de diciembre de 1872 (es decir, el semanario reaparece después de una interrupción de once meses) hasta el $N^{\circ} 40$, posiblemente del 5 de abril de 1873 .

Los ejemplares del semanario que hoy se conocen ponen de manifiesto que La Sabatina tuvo una inusitada periodicidad ${ }^{15}$. Sin embargo, como consecuencia del desorden que caracterizó a la prensa política de aquella época, en la columna de Prensa del semanario limeño El Correo del Perú aparece registrado semanalmente hasta el número del 23 de marzo de dicho año, lo que demuestra lo poco confiable que son las informaciones periodísticas puesto que el $\mathrm{N}^{\circ} 25$ es del 21 de enero y el siguiente, el $N^{\circ} 26$, de 28 de diciembre. Mal pudo haber habido, pues, un número cercano al 23 de marzo.

Durante la primera etapa de su vida, desde su aparición a mediados de 1871 hasta enero de 1872, La Sabatina tuvo un propósito preferentemente político y de apoyo a la candidatura de Manuel Pardo a la presidencia de la república; durante su segunda etapa, el primer trimestre de 1873, se transformó en una publicación agresiva que con gran facilidad manejaba el insulto contra los enemigos del gobierno civilista que se había establecido en agosto del año anterior. Sería necesario, pues, poder investigar las razones por las cuales desaparece de la circulación durante casi todo el año 1872, que fue

15 Dos ejemplos sirven para ilustrar lo indicado: el primero, de setiembre de $187 \mathrm{l}$ hasta fines de enero de 1872; el segundo, de diciembre de 1872 a abril de 1873 . De acuerdo con el material que se conoce y con las referencias recogidas, en ambos casos el semanario aparece en forma regular. 
precisamente el período durante el cual Pardo, primero, y su gobierno, después, necesitaron de mayor apoyo, mayor que el que le brindaba diariamente El Nacional. Lo que indica que es necesario repensar hasta donde tuvo como propósito exclusivo apoyar al naciente civilismo que desde abril de 1871 luchó exitosamente por asumir el poder.

\section{Contenido de La Sabatina}

Como este trabajo se hace teniendo a la vista una colección incompleta del semanario, no es posible asegurar que en los números desconocidos de La Sabatina no aparecen secciones distintas de las siguientes:

Sabatina. Editorial del semanario que, en algunas ocasiones, cubre más de una página completa. Todos estos editoriales aparecen suscritos por Luigi Vampa, el único seudónimo de Luis E. Márquez que se conoce. Con ese mismo seudónimo firmaba sus colaboraciones en El Nacional.

Revista de la prensa. En el siglo XIX, era corriente que diarios y revistas tuvieran una sección destinada a reproducir o comentar artículos o noticias aparecidos en otras publicaciones periódicas locales o del extranjero. Puesto que en su mayor parte eran reproducciones, no era frecuente que estuvieran firmadas.

Colaboradores y Buzón de La Sabatina. Estas dos secciones, junto con el Editorial, constituían la plataforma de ataque de la revista. Siempre estuvieron suscritas con seudónimo o se presentaban anónimamente.

Correspondencias. En casi todos los números conocidos de La Sabatina aparece la sección titulada Correspondencias en la que se reproducen extensas cartas, aparentemente suscritas en Nueva 
York, en las que su corresponsal -si es que este existió- se ocupa de asuntos relacionados con el progreso de los Estados Unidos aunque formula algunas diversas consideraciones relacionadas con la política peruana.

Ciencias, bellas letras y artes y Literatura. Las dos columnas del rubro son infaltables en La Sabatina. Como en todas las publicaciones periódicas de la época, es muy frecuente dentro de ellas la aparición de la denominada Revista de la moda, que en todos los casos aparece suscrita por María (i?). Durante la primera época de la publicación, los aspectos relacionados con la literatura forman parte de la primera de las columnas mencionadas; a partir del $\mathrm{N}^{\circ} 30$, la columna Literatura adquiere autonomía y pasa a tener una importancia mucho mayor. Esto confirma que, tal como ya se ha indicado, durante la segunda etapa de su vida La Sabatina tiene un propósito mucho más literario que el que había tenido hasta entonces. Como se verá más adelante, en esta sección se recogen textos suscritos por dos autores peruanos y cuatro españoles, aparte de otros breves cuya autoría no se reconoce. Se pueden asimilar a las secciones de Ciencias, bellas letras y artes y Literatura dos extensos textos de carácter literario: la novela La mujer de usted y el poema Evangelina. En ninguno de los casos se identifica al autor.

Inserciones. Bajo este título aparecen dos textos distintos, presumiblemente pagados, a favor del presidente Pardo: un extenso discurso del doctor Cesáreo Chacaltana (1845-1906), prominente civilista que fuera $2^{\circ}$ vicepresidente de la república en 1894 y que por entonces era uno de los directores de El Nacional, y una carta abierta del general Andrés Segura, otro civilista de importancia que llega a ser designado ministro. 


\section{Redactores de La Sabatina}

Los números de La Sabatina que se conocen recogen textos de 36 personas; de ellos, los de 8 aparecen con indicación de autor y 28 lo hacen con seudónimo. Hay muchos textos que aparecen sin firma o de los cuales es difícil establecer la paternidad como consecuencia del mal estado en que se encuentra la colección con que se ha trabajado. Como se verá más adelante, ha sido posible identificar a seis de los autores que suscriben los textos firmados; no se ha podido ubicar a Ricardo Sepúlveda y Carlos Coello. Mientras tanto, no hay forma de asegurar si los 27 seudónimos corresponden a otras tantas personas naturales o si algún redactor utilizaba más de un seudónimo, que es lo que suponemos.

Los textos debidamente suscritos pertenecen a dos autores peruanos y cuatro españoles. De la escritora tacneña Carolina Freyre de Jaimes (1844-1916), La Sabatina recoge una composición poética titulada En el álbum de F[lorencio] Héctor Varela, dedicada al periodista uruguayo avecindado en Buenos Aires que se encontraba en Lima en los días de la revolución de los coroneles Gutiérrez y que luego habría de publicar su historia de la Revolución de Lima (París, 1872). De Pedro Paz Soldán y Unanue (1839-1891), más conocido como Juan de Arona, el semanario recoge algo de su La línea de Chorrillos, publicada post mortem recién en 1894, lo que permite asegurar que parte del folleto de Arona estaba redactado cuando menos desde 20 años antes. Pero es posible que la relación de Márquez con Arona hubiera sido bastante estrecha porque La Sabatina publica en uno de sus números una parodia de su futuro Diccionario de Peruanismos (Buenos Aires, 1884) presentando un breve y malintencionado diccionario de limeñismos. Los siguientes son un par de ejemplos de las definiciones que se atribuyen a Arona: 
"Autonomía. Palabra que representa una de las cuatro mulas flacas que tiran del carro de la patriotería, yendo en compañía de unificación, americanismo y solidaridad. [...]

Probidad. Una máscara que puede llevarse todo el año sin sofocar a quien la lleva pero estrangulando el bolsillo del prójimo."

Los autores extranjeros cuyas obras se reproducen son poetas, dramaturgos y periodistas españoles, en su mayoría con una clara vocación por el humorismo. De José Selgas y Carrasco (1822-1882), poeta y escritor de tendencia moderada, La Sabatina recoge el artículo Admiración por la guerra que debe haber aparecido en el famoso semanario satírico El Padre Cobos (1854-55) que fundó y dirigió puesto que la mayor parte de sus obras son posteriores. A Rafael García y Santisteban (18291893 ) pertenecen las siete estrofas de unos simpáticos Cantares caseros que aparecen en el último número de nuestro semanario. Es posible que la letrilla iVivan las feas! provenga del volumen de composiciones festivas Mis primeros versos publicado en 1864 por el dramaturgo y poeta festivo español Constantino Gil y Luengo (1844-1914). De Ventura de la Vega (1807-1865), prestigioso poeta y dramaturgo español de origen argentino, es la composición Un amigo..., cuyo nombre completo no se puede apreciar por encontrarse quemado el borde de la página.

Los textos que aparecen con seudónimo presentan una situación curiosa: de los 28 que aparecen, once tienen un origen italiano: Luigi Vampa, Benedetto, Cucumetto, Rosso, Pipino, Gasparoni, Scorpioni, Disparafucile, Trabucco, Petruccio y El mayor Cavalianti ${ }^{16}$. Pero además de la observación anterior es posible formular

16 El resto de los seudónimos son muy simples: Simbad, Lacunza, Sammy, Moro viejo, Peruanos, Juan Lanas, Manuel, María, Clorinda, Una limeña, B.S., R.R., J.M., J, E. de Lu..., ***. 
otra relacionada con Italia: en varios de los artículos textos que aparecen sin firma se menciona a los Abruzzos, región ubicada en el centro de la península itálica al noreste de Roma y entre los Apeninos y el mar Adriático, que por entonces estaba ocupada por Austria, y se le considera como una especie de Arcadia. Esto nos permite intuir que Márquez pudo haber pasado buena parte del tiempo que estuvo en Europa, según se menciona más adelante, en aquella región tradicional de la actual Italia y que tuviera razones especiales para guardarle especial cariño. Estas mismas consideraciones permiten suponer que Márquez podría ser el autor de buena parte -o, inclusive, de todos- los artículos firmados con seudónimos de origen italiano, los mismos que cubren más de la mitad del texto de La Sabatina.

En la relación anterior se ha omitido la mención a dos de los seudónimos, El abate Faria y El abate Busoni: ambos corresponden a personajes de El Conde de Montecristo, la famosa novela de Alejandro Dumas publicada en 1844, lo que mueve a pensar que alguno de los redactores o el propio Márquez tenía un aceptable conocimiento de la novela romántica francesa.

Al término de la tediosa relación señalada es posible concluir que el semanario ha seguido los pasos de la mayoría de las publicaciones periódicas del siglo XIX: solo se puede identificar al director pues los demás posibles redactores guardan cuidadosamente el anonimato. Sin embargo, La Sabatina describe, en uno de sus primeros números, a sus posibles redactores:

\footnotetext{
"El primero es Luigi Vampa:

muy flaco y muy narigón, pero con un corazón mucho mejor que su estampa.

Viene después Cucumetto

Mozo de robusto lomo:

Tiene un ojo no sé como,
} 
Aunque es muy guapo sujeto.

Le sigue el bravo Pipino,

Que en las romanas campiñas

Sacó muchísimas quiñas

De un sarampión asesino.

Simbad, el mejor corsario

De la época moderna

Vistió en la ciudad eterna

El hábito mercedario.

Lacunza, crespo adalid

De la cuadrilla rapaz

Es un mozo muy capaz

De habérselas con el Cid.

Y, Sammy, el más perillán

Del gremio sabatinero,

Tiene un airecillo fiero

Y una cara de alemán.”

La información que puede extraerse de las estrofas anteriores es muy pequeña. Se limita a proporcionar el perfil de Márquez (que no coincide con las fotografías que de él se conocen) y permite suponer que uno de los redactores podría llamarse Samuel. Por lo tanto, de los responsables de La Sabatina solo puede identificarse a Luis Enrique Márquez.

\section{Luis Enrique Márquez}

La relativamente corta vida de Luis Enrique Márquez se desenvuelve entre el Perú, Chile, Estados Unidos, Ecuador y Europa -cuando menos en Bélgica e Italia- ${ }^{17}$. Nació en Lima en

17 Las primeras referencias biográficas de Márquez las proporciona José Domingo Cortés, quien aparentemente fue su amigo, en su Parnaso Peruano (Valparaíso, Imprenta Albión de Cox y Taylor, 1871). Noticias adicionales solo las ha proporcionado Manuel Zanutelli. 
julio de 1846 y fue hermano del poeta romántico José Arnaldo Márquez (1832-1903), catorce años mayor, y de la periodista y compositora Manuela Antonia Márquez (1844-1890). Poco se sabe de su vida hasta alrededor de 1865: se ausenta del Perú cuando tenía diez años de edad y pasa a Chile para educarse en el Instituto de Valparaíso, centro educativo que había fundado en el puerto chileno su hermano José Arnaldo, quien se encontraba deportado; en 1857 viaja a Estados Unidos, a raíz de la incorporación de su mencionado hermano mayor al cuerpo consular peruano; hacia 1861 enrumba hacia Europa, continúa su educación en Bélgica y debe haber pasado un buen tiempo en Italia, donde aprendió italiano. Reintegrado al Perú a mediados de la década de 1860 , se incorpora primero al cuerpo administrativo de la Marina y luego al Banco del Perú hasta que en 1866 inicia su actividad periodística como jefe de crónica del cada vez más influyente diario liberal limeño El Nacional y en la revista cultural El Cosmorama, quincenario dirigido por José Arnaldo (1867). Durante el segundo semestre de 1871 y los primeros meses de 1873 se le encuentra en la dirección de La Sabatina, semanario político y humorístico que apoyaba la candidatura presidencial de Pardo. Es posible que durante 1872 haya retornado a El Nacional. De 1875 a 1879 fue cónsul del Perú en Valparaíso; en 1881, después de batirse contra el invasor en las batallas de San Juan y Miraflores, partió al exilio en Ecuador de donde retorna en 1884 y es designado para asumir sucesivamente el consulado del Perú en Iquique (1884), la oficialía mayor del Ministerio de Relaciones Exteriores (1885) y el consulado del Perú en Chile (1885). De vuelta al Perú, obtuvo el premio otorgado por el Ateneo de Lima por su zarzuela La novia del colegial (1886). Fue uno de los organizadores y el primer presidente del Círculo literario (1886). Pero por entonces su salud estaba seriamente deteriorada y, víctima de una larga y penosa enfermedad, fallece en Lima en abril de 1888. 


\section{Márquez y su enemistad con Palma}

Una somera revisión de La Sabatina obliga al lector a preguntarse qué determinó (y, por lo tanto cuándo surgió) la violenta enemistad de Márquez para con Palma.

Anteriormente hemos mencionado que en la vida de La Sabatina hay dos épocas: en la primera, que cubre el segundo semestre de 1871 y parte de enero de 1872; no aparece allí mención alguna al futuro tradicionista que, por entonces, se desempeñaba como secretario del presidente Balta y senador por Loreto.

Luego de tres meses del asesinato de Balta, Palma se incorpora como fundador y redactor de El Cascabel. Y en cada uno de los números siguientes Palma publica sus Retratos parlamentarios, de tono festivo e irrespetuoso, y debe haber colaborado en las secciones denominadas Cascabeles, Pinceladas, Pinceladitas y Palotadas. No era pues pequeño el aporte de Palma en la campaña de oposición a Pardo. No tendría mayor interés proporcionar una relación de los ataques al gobierno pues todos están relacionados con la situación económica y con la adulación de la cual Pardo, en opinión de El Cascabel, era objeto.

Y ese es el momento en que, después de once meses de haber suspendido sus apariciones, en diciembre de 1872 reaparece $\mathbf{L a}$ Sabatina y emprende la defensa del gobierno valiéndose del principio deportivo que establece que la mejor defensa es un buen ataque. Sin embargo, lo que interesa en este trabajo son los ataques que recibe Palma, pues de los redactores de El Cascabel es el único atacado.

Cuando menos en cuatro de los quince números de esta segunda época de La Sabatina Márquez se ocupa de Palma. En el número con que reaparece $\left(\mathrm{N}^{\circ} 26\right.$, de diciembre de 1872$)$ Márquez lo ataca en forma descarnada: 
Prieta la cara y más prieta

El alma que Dios le dio,

Este prieto comenzó

Por dedicarse a poeta.

Y poniendo el castellano

Más molido que un ecce-homo

Hizo un tomo y otro tomo

Con un ardor africano.

Mas con negra inspiración

Entonces no se comía

Y aburrido, cierto día,

Se largó a una legación.

Regresó del extranjero

Y se metió a periodista,

A opositor, a tronchista,

A gancho y capitulero.

Fue más tarde secretario

Tierno, sumiso, indulgente

$\mathrm{Y}$ una ardilla como agente

De cualquier grande empresario. $[\ldots]^{18}$

En el mismo número, Márquez la emprende contra la madre de Palma, en términos que hacen recordar los textos que Felipe Pardo y Aliaga había dedicado, 35 años antes, a la cacica Calaumana, madre del mariscal Santa Cruz. Ninguno de estos insultos prestigia a los respectivos autores.

Tres semanas después, Márquez vuelve a la carga:
Allí está el niño de Angola
Que parece ánima enferma:

18 El texto está tomado de la biografía de Márquez publicada por Zanutelli ya citada (págs.189-190). Juzgo innecesario repetir todas las estrofas de la composición. 

El nieto de Na Guillerma,
El héroe de la pistola ${ }^{19}$.

Las instrucciones que debe haber recibido Márquez para defender al gobierno y sacar de la línea de combate al prestigiado Palma deben haber sido muy precisas puesto que La Sabatina concentra sus ataques en el tradicionista. En realidad, en el $\mathrm{N}^{\circ}$ 30, de 25 de enero de 1873, publica la tercera parte de una Galería periodística dedicada a Palma (lo que indica que en dos de los tres números anteriores de esta segunda época habrían aparecido la primera y segunda parte) en la que dice de Palma que "...su sección en "El Cascabel" es la más negra de los pasquines habidos y por haber". Refiriéndose a Palma (que en 1872 ya había publicado el primer volumen de sus Tradiciones y cuyos textos eran recibidos con gratitud por cuanta revista literaria aparecía en el Perú), insiste en su posible origen afroamericano:
Un negrito lanzó un grito
A la puerta del infierno
Y salió el diablo y le dijo
Aquí no gritan los negros ${ }^{20}$.

Después del último de los ataques conocidos aparecen otros diez números de La Sabatina, de los cuales se conocen solo tres en donde no aparecen nuevos insultos contra Palma lo que permitiría considerar la posibilidad de que nuestro escritor hubiera bajado el tono de sus ataques al gobierno de Pardo. Lamentablemente, careciéndose por ahora de colecciones completas tanto de La Sabatina cuanto de El Cascabel, no es posible sugerir ni siquiera conjeturar.

$19 \mathrm{~N}^{\circ} 29$, de 18 de enero de 1873. Cfr. Zanutelli, ob.cit., pág. 191.

$20 \mathrm{~N}^{\circ} 30$, de 25 de enero de 1872. Para bien o para mal, la colección que tenemos a la vista se encuentra tan deteriorada que impide tomar conocimiento en forma completa de otros textos de los ataques a Palma que cubren más de una columna. 
Las consideraciones anteriores nos permiten reparar en que a lo largo de la vida de don Ricardo Palma no todo fueron elogios. La trágica muerte de Balta, de quien había sido secretario durante cuatro años, y la aproximación de la fecha que marcaba el final del período para el cual había sido designado senador por Loreto señalan el fin de su vida pública, pero su indoblegable vocación por el periodismo le ofrecerá durante bastantes años más la ocasión de continuar insertado en la vida política, de cuyo buen sabor no se había olvidado.

Pero tampoco se habían olvidado de Palma ni Luis Enrique Márquez ni sus seguidores que, a partir de 1886, reunidos ya en el Círculo Literario, aplauden con fervor los comentarios desfavorables que le dedica González Prada.

Estas breves líneas no hacen sino confirmar que del ámbito de la historia y de la literatura queda mucho por investigar sobre lo ocurrido en el siglo XIX, pues por cada hoja que se levanta aparecen diez asuntos nuevos por aclarar. 